\title{
Adhesive strength of fiberglass posts treated with thio-urethane-based experimental silanes
}

\section{Purpose}

The aim of this study was to evaluate the adhesive bond strength of fiberglass posts treated with experimental silanes based on thio-urethane and submitted to thermo and mechanical cycles.

\section{Materials and Methods}

Bovine roots were divided into six groups: RX-RU2 (RelyX CP + RelyX U200); PETMPHDDI-RU2 (PETMP-HDDI + RelyX U200); PETMP-BDI-RU2 (PETMP-BDI + RelyX U200); RX-RU (RelyX CP + RelyX Ultimate); PETMP-HDDI-RU (PETMP-HDDI + RelyX Ultimate); PETMP-BDI-RU (PETMP-BDI + RelyX Ultimate). One slice from each root third $(n=10)$ was submitted to the push-out test and the values evaluated with $R$ Program statistical analysis, while the failure pattern assessed in percentage.

\section{Results}

Among root thirds, RX-RU2 promoted greater strength at the cervical and apical thirds; PETMP-HDDI-RU2 showed highest values at the three thirds; and PETMPBDI-RU2 was strongest at the apical third. RX-RU presented higher strength the apical third, and PETMP-HDDI-RU and PETMP-BDI-RU had similar values at the three thirds. In each root third, PETMP-HDDI-RU2 showed similar strength at all thirds, and similar strength at the apical third was observed for other associations. Mixed and adhesive failures predominated.

\section{Conclusion}

Experimental silanes promoted different bond strength values in the adhesion of fiberglass posts to the root thirds, with better results for PETMP-HDDI silane. The root region did not influence the failure pattern and most slices showed mixed (MCDP) or adhesive (ADP) failure.

Keywords: Fiberglass post, Experimental silane, Resin cement, Adhesive strength, Failure pattern

\section{Introduction}

The current concept of dentistry is a conservative proposal that preserves the largest amount of healthy tooth tissue when affected by caries disease or trauma. Treatment for severely affected teeth was previously extraction; however, protocols that are more conservative are now commonly used in dental clinics. Direct and indirect restorations with different materials, endodontic treatments with root retainers and prosthetic crowns are some examples of the conservative dentistry to rehabilitate the compromised dental structure.

Endodontic treatments with root retainers are procedures for teeth severely destroyed and that do not allow the reconstruction of the crown with direct restorative materials. Root retainers are available in different materials and shapes; however, studies have shown greater effectiveness with fiberglass posts $(1,2)$. These retainers replaced metal posts because they offer better color similarity to natural tooth, they preserve the dentin

\author{
Vitoria Massoneto Piccolli ${ }^{1}$ \\ Carmem Silvia Pfeifer ${ }^{2}$ (D), \\ Ana Paula Piovezan \\ Fugolin² (D), \\ Marcos Cezar Pomini' ${ }^{1}$, \\ Roberta Araujo de Paula \\ Ramos' ${ }^{1}$, \\ Rafael Leonardo Xediek \\ Consani ${ }^{3}$
}

ORCIDIDs of the authors: V.M.P. 0000-0003-2768-4177; C.S.P. 0000-0002-1587-3838; A.P.P.F. 0000-0002-3107-5430 M.C.P. 0000-0001-8129-7165; R.A.P.R. 0000-0001-7138-5305; R.L.X.C. 0000-0003-4122-9234

'State University of Campinas, Piracicaba Dental School, SP, Brazil

${ }^{2}$ Oregon Health \& Science University, School of Dentistry, Biomaterials and Biomechanics, USA

${ }^{3}$ State University of Campinas, Piracicaba Dental School, Department of Prosthodontics and Periodontology, SP, Brazil Corresponding Author: Rafael L. X. Consani E-mail: rconsani@fop.unicamp.br Accepted: 21 October, 2020 
of the root canal and they improve the flexibility as well as the mechanical properties of the restorations.

Fiberglass posts are associated to adhesive cementation, favoring protocol acceptance due to good clinical results (1). Resin cements are classified according to the activation system: chemical (conventional), physical (photo activation by light) or dual activation (chemical and physical). Dual activation cements show improved mechanical properties compared to chemical activation cements or photo activated only cements (3).

Dual activation cements also have chemical activation, and are used to fix fiberglass posts compensating the attenuation of the photo activation in deeper regions of the root canal. In addition, resin cements can interact with the root dentin substrate in different ways, depending on the adhesion protocol used. The classification of dual activation resin cements is based on conventional or self-adhesive cements and whether they are associated to bonding agents. Conventional cements are combinations of adhesive systems that can be etch-and-rinse or self-conditioning cements (4). Self-conditioning resin cements do not require prior dentin treatment, such as acid etching, primer and adhesive applications, since the organic matrix containing multifunctional methacrylate monomers interacts chemically with the hydroxyapatite of dental tissue $(5,6)$. However, resin cements and the preparation of the root canal for installation of the retainer can promote failures in the interface post-adhesive-cement-dentin, being the main factor in the debonding of the fiberglass post from the root canal (7). Therefore, new materials had to be developed in order to improve the adhesive bonding technique to dentin and to decrease clinical failure. Thus, researchers have incorporated thio-urethane oligomers into resin materials, improving the resistance to fracture, reducing the polymerization shrinkage stress and increasing dentin adhesion $(8,9)$.

In addition, the association of 1,6 hexanediol dimethacrylate (HDDMA) cross-linking agent with thio-urethane in acrylic resin activated by microwave energy resulted in the thio-urethane chain breaking, forming a linear polymer harmful to the polymerization of poly methyl methacrylate. However, the HDDMA addition in up to $20 \%$ by weight, not associated with thio-urethane, significantly improved the properties studied (10). Based on this considerations, it would be timely and current to verify the effect of the thio-urethanes addition in experimental silanes and verify the effect on the bond strength of resin cements to fiberglass posts.

The aim of this study was to evaluate the adhesive bond strength of fiberglass posts treated with commercial or experimental silanes based on thio-urethane, fixed with resin cement in root canal, and submitted to thermo and mechanical cycles. The study null hypothesis was that there would be no differences in the bond strength values among the cements, silanes or root thirds.

\section{Materials and methods}

\section{Synthesis of experimental silanes}

The thio-urethanes utilized as silanes were prepared in the Oregon Health and Science University laboratories. Two oligomers were synthetized in solution with catalytic amounts of triethylamine. Multi-functional thiol-pentaerythritol tetra-3-mercaptopropionate (PETMP) was combined with two di-functional isocyanates: 1,6-hexanedioldiissocyante (HDDI - aliphatic) or 1,3-bis (1-isocyanato-1- methylethyl) benzene (BDI - aromatic), as shown in a previous study (11).

\section{Experimental groups}

Teeth were randomly divided into 6 groups $(n=10)$ : $R X$ RU2 (RelayX CP silane and RelyX U200 resin cement - Control); PETMP-HDDI-RU2 (PETMP-HDDI experimental silane and RelyX U200); PETMP-BDI-RU2 (PETMP-BDI experimental silane and RelyX U200); RX-RU (RelyX CP commercial silane and RelyX Ultimate resin cement - Control); PETMP-HDDI-RU (PETMP-HDDI experimental silane and RelyX Ultimate); PETMP-BDI-RU (PETMP-BDI experimental silane and RelyX Ultimate). RelyX Ceramic Primer - lot 1822100538; RelyX U200 - lot 5174278; RelyX Ultimate - lot 1906300185; Single Bond Universal - lot 1908600389; Filtek Z250 - lot 1820600456 and Vitrebond - lot 18100642 were manufactured by 3M ESPE (Nova Odessa, SP, Brazil).

\section{Tooth preparation}

Freshly extracted bovine lower incisors were kept in distilled water under refrigeration until use. The criterion of external anatomical similarity of the bovine teeth was considered for the selection of straight roots with cervical canal diameter of $2.0 \mathrm{~mm}$ and closed apices. The teeth were cleaned with a scalpel blade to remove the residual periodontal ligament. The root length with $16 \mathrm{~mm}$ was checked with a digital caliper (Isomet 1000; Buchler, Lake Bluff, IL, USA). The pulp was removed with a Kerr-type endodontic file (Maillefer - Dentsply, Petropolis, RJ, Brazil).

\section{Endodontic treatment}

Root canal treatment was performed with biomechanical preparation (step-back technique) and Kerr endodontic files (Maillefer - Dentsplay). The working length was at $1 \mathrm{~mm}$ before the foramen with an apical stop set at diameter 55 . The canal was irrigated with $1 \%$ sodium hypochlorite (Asfer Chemical Industry; Sao Caetano, SP, Brazil), saline solution (ADV, Nova Odessa, SP, Brazil), final irrigation with 17\% ethylene diamine tetra acetic acid (Formula \& Action, Sao Paulo, SP, Brazil), washed with saline solution and dried with absorbent cones (Dentsply Malleifer, Germany). Canal filling was done by lateral condensation using Gutta Percha cones (Dentsply, Malleifer, Germany) and calcium hydroxide-based cement (Sealer 26; Dentsply Malleifer, Germany). The canal entrance was sealed with Vitrebond (3M-ESPE), and the teeth kept in relative humidity in microbiological greenhouse (Prolab; Sao Paulo, SP, Brazil) at $37^{\circ} \mathrm{C}$ for 7 days.

\section{Root canal preparation}

After storage, the canal filling material was removed with a drill (\#3 Exacto; Angelus, Londrina, PR, Brazil) obtaining a depth of $12 \mathrm{~mm}$ and preserving $4 \mathrm{~mm}$ apical endodontic treatment. Before cementation, the post was sectioned with a diamond disc (KG Sorensen) in a high speed rotating de- 
vice (KaVo Industry; Joinville, SC, Brazil) cooled with water, establishing a 16- $\mathrm{mm}$ length. The length excess corresponding to coronary portion was $4 \mathrm{~mm}$. The posts were cleaned with $70 \%$ alcohol for $30 \mathrm{~s}$ and air dried for $5 \mathrm{~s}$. A layer of RelyX CP conventional silane (3M-ESPE) or experimental (PETMP-HDDI or PETMP-BDI) silanes was applied to the posts of each group with microbrushes (KG Brush; Sorensen) and dried with a light air jet for $5 \mathrm{~s}$. The posts were fixed with RelyX U200 or RelyX Ultimate self-adhesive resin cements (3M-ESPE) applied to the canal with a Centrix syringe (DFL, Rio de Janeiro, RJ, Brazil). The cement application protocols recommended by the manufacturer were: RelyX U200: Canal washing for $30 \mathrm{~s}$; excess moisture removal with absorbent cones keeping the dentin moist; cement manipulation mixing the base paste with the catalyst paste for $20 \mathrm{~s}$ until to obtain a homogeneous mixture; cement application from the apical to cervical region with a syringe. RelyX Ultimate: Canal conditioning with $37 \%$ phosphoric acid for 15 s; washing with water for $30 \mathrm{~s}$; excess moisture removal with absorbent cones keeping the dentin moist; active application of the Single Bond Universal adhesive with a microbrush for 20 $\mathrm{s}$; excess adhesive removal with absorbent paper; cement manipulation mixing the base paste with the catalyst paste for 20 s until to obtain a homogeneous mixture; and cement application from the apical to cervical region with a syringe.

The posts were inserted into the canal with light digital pressure. After removing the excess, the cement was photo activated for $40 \mathrm{~s}$ with the Bluephase $\mathrm{G} 2$ device (Ivoclar-Vivadent, Schaan, Liechtenstein - $1200 \mathrm{~mW} / \mathrm{cm}^{2}$ irradiance), according to the manufacturer's recommendations. A length of $20 \mathrm{~mm}$ of the post was fixed into the canal; the remaining $4 \mathrm{~mm}$ was used as a guide to standardize the distance between the photo activator tip and the cervical root. Periapical radiographs were taken to check the condition of the endodontic treatment and the fiberglass post fit.

\section{Tooth crown preparation}

Cores were filled with resin composite (Filtek Z250; 3M-ESPE) using the incremental technique. Etching was done with $37 \%$ phosphoric acid (Biodynamics, Ibipora, PR, Brazil) for $15 \mathrm{~s}$, washing with distilled water, drying with cotton, and active application of the Single Bond Universal adhesive (3M-ESPE) with a microbrush (KG Sorensen) for $20 \mathrm{~s}$. The adhesive was dried with a light air jet for $5 \mathrm{~s}$, and photo activated for $20 \mathrm{~s}$ (Bluephase G2; Ivoclar Vivadent). Each resin composite increment was photo activated for 20 s (Bluephase G2; Ivoclar Vivadent), and the crown delimitation was achieved with a \#2135 drill (KG Sorensen). Based on previous work (12), the crowns were made with self-curing acrylic resin (Vipi Cril; Vipi, Pirassununga, SP, Brazil) in a silicone molds (Zetalabor; Zhermack, Rovigo, Italy) obtained from a premolar tooth. After finishing and polishing, the crowns were fixed with RelyX U200 self-adhesive resin cement (3M-ESPE) manipulated according to the manufacturer's recommendations.

\section{Mechanical cycling}

The tooth root was embedded in rigid PVC tubes (Tigre, Osasco, SP, Brazil) with $2 \mathrm{~mm}$ in height by $2.5 \mathrm{~mm}$ in diameter containing acrylic resin (Vipi Cril; Vipi). The teeth were submitted to mechanical cycling with $1.2 \times 10^{6}$ cycles in a device for mechanical fatigue (ERIOS, ER 11000, Sao Paulo, SP, Brazil). Repetitive axial impacts with a load of $50 \mathrm{~N}$ at 2 $\mathrm{Hz}$ frequency were made by a metal piston on the crown immersed in distilled water at $37^{\circ} \mathrm{C}(13)$.

\section{Thermal cycling}

The teeth were subjected to 500 thermal cycles (M-TWS-1; Willytec, Munich, Germany) in alternate baths of distilled water at $5-55^{\circ} \mathrm{C}\left(30 \mathrm{~s}\right.$ at $5^{\circ} \mathrm{C}+5 \mathrm{~s}$ of transfer $+30 \mathrm{~s}$ at $55^{\circ} \mathrm{C}$ $+5 \mathrm{~s}$ of transfer to the next cycle), according to the ISO/TS 11405:2000(E) standard (14).

\section{Push-out bond strength}

After thermal and mechanical cyclings, the roots separated from the crowns were fixed on acrylic plates with sticky wax (Kota; Sao Paulo, SP, Brazil), and positioned on the metallographic cutter (Isomet 1000; Buehler) for crosscuts. Slices with 1-mm thickness from each root third $(n=10)$ were obtained and checked with a digital caliper (Mitutoyo; Suzano, SP, Brazil). The root slices (Figure 1) submitted to the pushout test in a universal testing machine (Instron 4411; Norwood, MA, USA) which was positioned to displace the fiberglass post portion in the apex-crown direction with a speed of $0.5 \mathrm{~mm} / \mathrm{min}$. Metallic pointers with active tips compatible with the canal diameter were used allowing the force to be executed only on the post portion without touching the canal wall. The load was recorded in $\mathrm{N}$ and the bond strength values calculated in $\mathrm{MPa}$, dividing the force $(\mathrm{N})$ by the adhesive area $\left(\mathrm{mm}^{2}\right)$ which was calculated with the formula:

$A D=\pi(R+r)\left[\left(h^{2}+(R-r)^{2}\right]^{0.5}\right.$

Where: $\pi=$ constant 3.1416; $R=$ canal coronal radius $(\mathrm{mm})$; $\mathrm{r}=$ canal apical radius $(\mathrm{mm}) ;$ and $\mathrm{h}=$ root slice thickness.

\section{Failure pattern}

The failure pattern was analyzed with a stereoscopic 50x magnifying glass (Leica MZ75; Sao Paulo, SP, Brazil) and classified as ACP (Adhesive - at cement-post interface); ADP (Adhesive - at dentine-post interface), and MCDP (Mixed - at cement-dentine-post interfaces). Representative slices of each

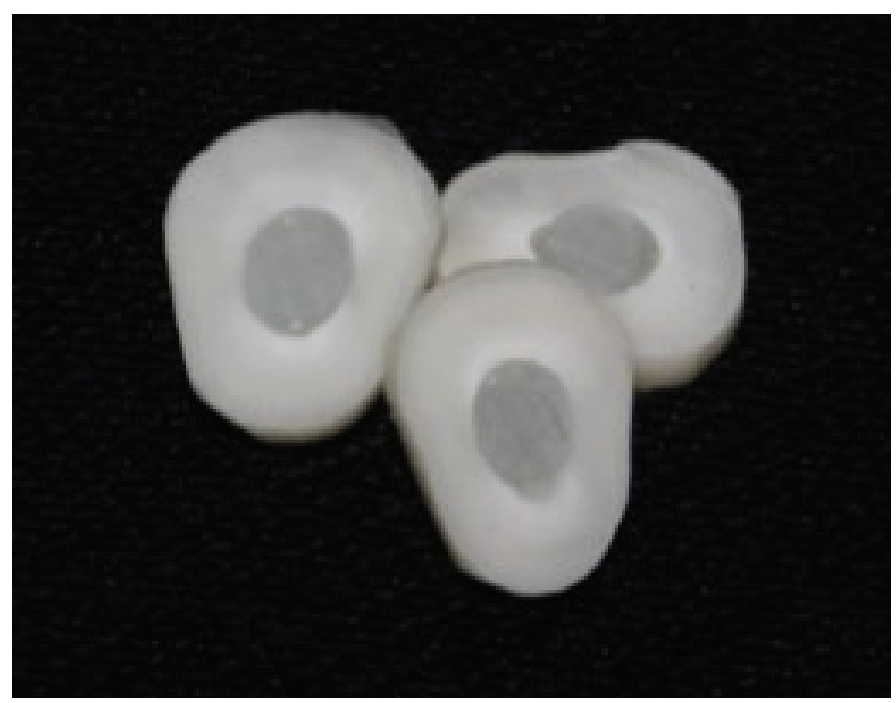

Figure 1. Root slices 1-mm thickness. 
failure pattern were covered with a gold-palladium layer in a metallizer (Bal-Tec SCD050; Sputter Coater, Sao Paulo, SP, Brazil) and observed with SEM (Jeol, JSM 5600LV; Tokyo, Japan).

\section{Statistical analysis}

The values of the bond strength were submitted to exploratory analyzes and the data did not meet the assumptions of an analysis of variance (ANOVA). After descriptive and exploratory data analysis, a generalized linear model was estimated since the study design was subdivided in plots. The $\mathrm{R}$ Program Core Team made the statistical analysis for pushout test values, (A language and environment for statistical computing. R Foundation for Statistical Computing. Vienna, Austria; 2019), considering a significance of 5\% (15).

\section{Results}

\section{Shear bond strength}

The means and standard deviations of the bond strength (MPa) for the cement, silane and root third factors are shown in Table 1. There was a triple interaction between the study factors. When the comparison was among root thirds (in row), RX-RU2 (control) showed significantly greater strength at the cervical and apical thirds; PETMP-HDDI-RU2 had similar values at the three thirds; and PETMP-BDI-RU2 had greater strength at the apical third. RX-RU (control) showed significantly greater resistance at the apical third; and PETMP-HDDI-RU and PETMP-BDI-RU had similar values at the three thirds. Comparing each root third (column), PETMP-HDDI-RU2 provided a similar strength at the three thirds, and similar values were found for the apical third at the RXRU and PETMP-BID-RU groups.

Table 1. Means (standard deviation) of the bond strength (Mpa) in relation to the factors cement, silane and root third. ${ }^{1}$ Control. * It differs significantly from RelyX U200 cement in the same conditions as silane and third $(p<0.05)$. Means followed by different letters (uppercase letters in row comparing thirds and lowercase letters in the column comparing silane in each cement type) differ from each other $(p<0.05)$. $P$ (cement) $=0.0010 ; p$ (silane) $<0.0001 ; p$ (cement $x$ silane $)=0.0005 ; p($ third $)=0.0245 ; p$ (cement $x$ third $)=0.0687 ; p$ (silane $x$ third $)=0.1222$.

\begin{tabular}{|c|c|c|c|c|}
\hline \multirow{2}{*}{ Cement } & \multirow{2}{*}{ Silane } & \multicolumn{3}{|c|}{ Root third } \\
\hline & & Cervical & Middle & Apical \\
\hline \multirow{4}{*}{$\begin{array}{l}\text { RelyX } \\
\text { U200 }\end{array}$} & ${ }^{1} \mathrm{RX}$ & $\begin{array}{c}8.58(3.57) \\
\mathrm{Ab}\end{array}$ & 6.71 (1.85) Bb & $\begin{array}{c}8.64(3.63) \\
A b\end{array}$ \\
\hline & PETMP- & $14.77(4.60)$ & 15.64 (4.54) & $14.95(4.33)$ \\
\hline & HDDI & $\mathrm{Aa}$ & $\mathrm{Aa}$ & $\mathrm{Aa}$ \\
\hline & PETMP-BDI & $\begin{array}{c}2.64(2.37) \\
\mathrm{Bc}\end{array}$ & $\begin{array}{c}4.67(4.29) \\
\mathrm{ABb}\end{array}$ & $\begin{array}{c}9.17(9.03) \\
\text { Ac }\end{array}$ \\
\hline \multirow{3}{*}{ RelyX U } & ${ }^{1} \mathrm{RX}$ & $\begin{array}{c}8.32(4.86) \\
\mathrm{Bb}\end{array}$ & $\begin{array}{c}* 10.17(5.00) \\
\text { ABab }\end{array}$ & $\begin{array}{c}11.04(5.17) \\
\mathrm{Aa}\end{array}$ \\
\hline & $\begin{array}{l}\text { PETMP- } \\
\text { HDDI }\end{array}$ & $\begin{array}{c}12.37(3.20) \\
\mathrm{Aa}\end{array}$ & $\begin{array}{c}12.59(4.08) \\
\mathrm{Aa}\end{array}$ & $\begin{array}{c}13.23(4.30) \\
\mathrm{Aa}\end{array}$ \\
\hline & PETMP-BDI & $\begin{array}{c}* 9.27(4.92) \\
\mathrm{Ab}\end{array}$ & 9.48 (2.55) Ab & $\begin{array}{c}8.81(5.43) \\
A b\end{array}$ \\
\hline
\end{tabular}

\section{Failure pattern}

Table 2 shows the failure pattern as a function of the factors root third, cement and silane. The root region did not influence the failure pattern and most slices showed mixed (MCDP) or adhesive (ADP) failures. In the cervical third, the majority of failures was MCDP in the RX-RU2 group and ADP for the PETMP-HDDI-RU2 and PETMP-BDI-RU2 groups. Additionally, most of the failures was MCDP in all associations with RelyX Ultimate. In the middle and apical thirds, the majority of failures was MCDP or ADP in all associations with RelyX U200 or RelyX Ultimate.

\section{Discussion}

This study evaluated the in vitro the bond strength of fiberglass posts treated with commercial or experimental silanes

Table 2. Failure pattern (number /\%) in relation to the factors root third, cement and silane. ACP (Adhesive - at cement-post interface); ADP (Adhesive - at dentine-post interface); MCDP (Mixed - at cement-dentine-post interfaces). 'Control.

\begin{tabular}{|c|c|c|c|c|c|}
\hline \multirow{2}{*}{$\begin{array}{l}\text { Root } \\
\text { third }\end{array}$} & \multirow{2}{*}{ Cement } & \multirow{2}{*}{ Silane } & \multicolumn{3}{|c|}{ Failure pattern } \\
\hline & & & ACP & ADP & MCDP \\
\hline \multirow{6}{*}{ 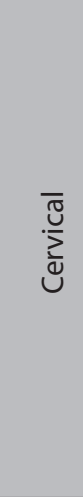 } & \multirow{3}{*}{$\begin{array}{l}\text { RelyX } \\
\text { U200 }\end{array}$} & ${ }^{1} \mathrm{RX}$ & $3 / 33.3 \%$ & $1 / 11.1 \%$ & $5 / 55.6 \%$ \\
\hline & & $\begin{array}{l}\text { PETMP- } \\
\text { HDDI }\end{array}$ & $1 / 11.1 \%$ & $5 / 55.6 \%$ & $3 / 33.3 \%$ \\
\hline & & $\begin{array}{l}\text { PETMEP- } \\
\text { BDI }\end{array}$ & $0 / 0.0 \%$ & $5 / 55.6 \%$ & $4 / 44.4 \%$ \\
\hline & \multirow{3}{*}{$\begin{array}{l}\text { RelyX } \\
\text { Ultimate }\end{array}$} & ${ }^{1} \mathrm{RX}$ & $0 / 0,0 \%$ & $4 / 40.0 \%$ & $6 / 60 \%)$ \\
\hline & & $\begin{array}{l}\text { PETMP- } \\
\text { HDDI }\end{array}$ & $0 / 0.0 \%$ & $1 / 12.5 \%$ & $7 / 87.5 \%$ \\
\hline & & $\begin{array}{l}\text { PETMEP- } \\
\text { BDI }\end{array}$ & $0 / 0.0 \%$ & $3 /(33.3 \%$ & $6 / 66.7 \%$ \\
\hline \multirow{6}{*}{$\frac{\frac{\lambda}{\frac{\partial}{\sigma}}}{\frac{0}{\partial}}$} & \multirow{3}{*}{$\begin{array}{l}\text { RelyX } \\
\text { U200 }\end{array}$} & ${ }^{1} \mathrm{RX}$ & $0 / 0.0 \%$ & $5 / 55.6 \%$ & $4 / 44.4 \%$ \\
\hline & & $\begin{array}{l}\text { PETMP- } \\
\text { HDDI }\end{array}$ & $1 / 10 \%$ & $4 / 40.0 \%$ & $5 / 50 \%$ \\
\hline & & $\begin{array}{l}\text { PETMEP- } \\
\text { BDI }\end{array}$ & $2 / 22.2 \%$ & $3 / 33.3 \%$ & 4 / $44.4 \%$ \\
\hline & \multirow{3}{*}{$\begin{array}{l}\text { RelyX } \\
\text { Ultimate }\end{array}$} & ${ }^{1} \mathrm{RX}$ & $0 / 0.0 \%$ & $2 / 20 \%$ & $8 / 80 \%$ \\
\hline & & $\begin{array}{l}\text { PETMP- } \\
\text { HDDI }\end{array}$ & $0 / 0.0 \%$ & 4 / $44.4 \%$ & $5 / 55.6 \%$ \\
\hline & & $\begin{array}{l}\text { PETMEP- } \\
\text { BDI }\end{array}$ & $0 / 0.0 \%$ & $5 / 55.6 \%$ & $4 / 44.4 \%$ \\
\hline \multirow{6}{*}{$\frac{\overline{0}}{\frac{\pi}{2}}$} & \multirow{3}{*}{$\begin{array}{l}\text { RelyX } \\
\text { U200 }\end{array}$} & ${ }^{1} \mathrm{RX}$ & $0 / 0.0 \%$ & $5 / 55.6 \%$ & $4 / 44.4 \%$ \\
\hline & & $\begin{array}{l}\text { PETMP- } \\
\text { HDDI }\end{array}$ & $2 / 20 \%$ & $6 / 60 \%$ & $2 / 20 \%$ \\
\hline & & $\begin{array}{l}\text { PETMEP- } \\
\text { BDI }\end{array}$ & $0 / 0.0 \%$ & $4 / 44.4 \%$ & $5 / 55.6 \%$ \\
\hline & \multirow{3}{*}{$\begin{array}{l}\text { RelyX } \\
\text { Ultimate }\end{array}$} & ${ }^{1} \mathrm{RX}$ & $0 / 0.0 \%$ & $5 / 55.6 \%$ & $4 / 44.4 \%$ \\
\hline & & $\begin{array}{l}\text { PETMP- } \\
\text { HDDI }\end{array}$ & $1 / 11.1 \%$ & $2 / 22.2 \%$ & $6 / 66.7 \%$ \\
\hline & & $\begin{array}{l}\text { PETMEP- } \\
\text { BDI }\end{array}$ & $0 / 0.0 \%$ & $4 / 44.4 \%$ & $5 / 55.6 \%$ \\
\hline
\end{tabular}


based on thio-urethane, fixed with resin cements on roots with conventional endodontic technique and subjected to thermal and mechanical cycling. The study hypothesis that there would be no difference in the bond strength values between cements, silanes or root thirds was rejected, since there was a statistically significant difference in the interaction between these factors.

The push-out test assesses in vitro the bond strength of the adhesive cementation interface in different protocols. In addition, the push-out test permits a more homogeneous stress distribution, less variability during the mechanical test, and reduction of premature failures (16). This desired methodological condition was obtained in the current study.

Investigations evaluating bonding methods of fiberglass posts to root dentin have shown different results in relation to canal regions. Higher bond strength values occurred in the cervical region, since the resin cement is submitted to photo and chemical activation intensities in this region, obtaining a better polymerization rate (17). After acid etching, the canal dentin area is responsible for the greatest adhesive strength of the bond, but not all areas exhibit similar responses to the acid etching (18). The types of root canal surface etching have different effects on the bond strength of fiberglass posts to root dentine; however, all evaluated surface treatment methods increased the adhesive strength when compared to the control samples (19).

Table 1 shows different values of bond strength in the interface between the fiberglass post and dentine in each root canal region. In addition to the other study factors, these differences seem to be dependent mainly on the interaction between silane and adhesive cement. In the comparison among root thirds, RX-RU2 (Control) provided significantly greater strength at the cervical and apical thirds; PETMP-HDDI-RU2 had similar values at the three thirds; and PETMP-BDI-RU2 presented the higher value at the apical third. RX-RU (Control) showed significantly greater strength at the apical third, and PETMP-HDDI-RU and PETMP-BDI-RU demonstrated similar values at the three thirds. Comparing each root third, PETMP-HDDI-RU2 showed similar strength at the three thirds, and similar values were observed at the apical third for the RX-RU and PETMP-HDDI-RU groups.

Besides the influence of the interaction between silane and adhesive cement on the fiberglass posts bond strength, the current study showed that the cement type and thermo-mechanical aging could also significantly affect the bond. Previous study showed that the pull-out bond strength was significantly affected by the cement type and ageing. RelyX ARC showed the highest bond strength before thermo-mechanical loading; however, the strength values decreased significantly after the procedure (20).

In this study, the interaction between silane and adhesive cement did not promote a similar behavior pattern that occurs by the difference of the photo activation intensity on the cervical portion compared to deeper regions of the root canal, and the consequent mechanical strength value related to polymerization rate. However, fiberglass posts are subjected to several other factors that can influence the cement-dentine-post bond quality. Among them, length, diameter, shape, surface structure and type of the post, cement layer thickness, application methods of the resin cement, and root canal treatment types (21).
Studies have shown a higher value of bond strength on the root apical region, and others have claimed that the bond strength on dentine close to the pulp is considered only 30 to $40 \%$ of the strength on peripheral dentine $(22,23)$. A relationship exists between the dentine area available for bonding and the bond strength obtained. The smaller the dentine thickness near the pulp, the larger the dentinal tubule area (24). In addition, there are several structural differences between coronal and intra radicular dentine substrates (25). The literature reports differ between a study showing that the retention level improves with the increase of the length of the cemented post in the root canal, and other suggesting that the retention value of the fiberglass post to dentine worsens with the deepening of the canal $(26,27)$.

In general, greater shear bond strength was observed for commercial cements associated with PETMP-HDDI experimental silane when compared to the RX silane and RX-PETMP-BDI associations, except at the apical region with the RU cement in all associations. On the other hand, the PETMP-HDDI silane associated to each cement type showed greater strength at all root thirds, while the RU cement showed the greatest strength at the cervical third.

Hyphrophobic silane compounds used to modify the surface of materials, whether based or not on silica, alter the bond quality between organic and inorganic materials (28). This fact could have a significant effect on the chemical and mechanical properties of experimental silanes in relation to adhesive interface strength. As such, different silane types were used to modify the surface of inorganic materials in order to improve the adhesion to organic materials (29). Maybe for that same reason, resin materials incorporated with thio-urethane additives have provided some advantages over the mechanical properties of non-additive materials (11).

The covalent interaction of thio-urethane with methacrylate occurs by transferring the pending functionality of the thiol in the oligomer chain. This chain transfer reaction delays the gelling or vitrification of the material, providing a higher level of monomer conversion, reducing polymerization stress, improving the network homogeneity and increasing the strength to fracture toughness $(8,30,31)$. These effects have positive consequences for the chemical-mechanical properties of these experimental polymeric materials.

Highest adhesive strength was observed for PETMP-HDDI. Probably, this experimental silane imparted greater toughness and fracture toughness to posts adhesion, since the polymerization of resin materials added with thio-urethanes promote a more stable adhesive interface (32). Although this relationship probably exists with PETMP-BDI silane, the highest adhesive strength value for this material occurred only on the apical third with both commercial cements. The difference in composition between the PETMP-HDDI and PETMP-BDI silanes may have caused the difference in adhesion levels among the root thirds, although this assumption should be checked in other studies evaluating the physical-chemical behavior of these experimental silanes.

In this sense, the adhesive resin for fixing fiberglass posts also needs improved the mechanical properties, since endodontically treated teeth are subjected to repetitive impact forces of different intensities. Moreover, the polymerization shrinkage reduction and the lesser stress level occurred in resin materials modified by thio-urethane may significantly 
contribute to adhesive strength, especially at the bonding interface (9). Based on these considerations, it is possible that the improvement observed in the mechanical properties of commercial adhesive cements, when associated to PETMP-HDDI silane, can stabilize the bond strength of fiberglass posts to the root canal over long time.

Most of the root slices presented MCDP or ADP failures (Table 2), and the failure pattern was not similar among the different root regions. At the cervical third, the majority of failures was MCDP for RX-RU2 and ADP for PETMP-HDDI-RU2 and PETMP-BDI-RU2 groups; additionally, most of the failures was MCDP in all associations with RelyX Ultimate. At the middle and apical thirds, the majority of failures was MCDP or ADP for all associations with RelyX U200 or RelyX Ultimate.

A previous study showed that silane impaired, or generally had no effect on the bond strength of self-adhesive resin cements to fiberglass posts, and the bond strength was greater than for conventional cement when the posts were not silanized. There was also a predominance of adhesive failures in all groups, with a greater number of mixed failures when the posts were silanized (33). This fact seems similar to the result of the current study regarding the failure types.

Fiberglass posts without silane application showed a smoother surface, reducing the mechanical locking with adhesive cement (34). Therefore, as the PETMP-HDDI and PETMEP-BDI silanes were able to increase the bond strength, it is assumed that the greater the strength required for dislodging the fiberglass posts, the greater the occurrence of mixed or cohesive failures, as occurred in this investigation. Thus, further studies are needed with different methods of silane application to understand the adhesive mechanisms that could improve the bond strength.

Another factor that may be related to reduction of adhesive failures with PETMP-HDDI and PETMEP-BDI silanes is be the amount of polymerization stress occurring between the fiberglass post and root dentine. Since the modulus of elasticity of resin cements is less than for fiberglass posts and root dentin, a higher stress concentration would occur at the adhesive interface (35). In this sense, the reaction between low glass transition oligomer and the methacrylate network can increase the modulus of elasticity, toughness and fracture strength of resin cements, when compared to methacrylate without additive (9). In addition, a photo elastic study showed that the different endodontic retainer types influenced the stress distribution on the root canal, and that the fiberglass post is the best choice for restoring endodontically compromised teeth, since a smaller stress value may increase the longevity and reduce the possibility of failures (36).

Another interesting report was that the bond strength values were not similar between groups with fiberglass posts of different diameters and there was no significant difference between the root regions in all groups. The failures were predominantly adhesive between resin cement and the post; however, the post with the best adaptation to the root canal showed a higher bond strength value (21).

In the current study, the roots were submitted to thermal and mechanical cycles simulating in vitro conditions for endodontic treatment. It is possible that the aging of the interface formed between root canal and fiberglass post, when fixed with commercial cements associated with the PETMP-HDDI or PETMEP-BDI silanes, result in similar marginal microleakage in the long term. However, the failure pattern was not similar among the root regions, since most of the slices presented mixed or adhesive cement-post failure, a fact that would may justify the application of these materials in clinical endodontic procedures. Moreover, a previous study showed that thermal stress increased the marginal microleakage level mainly due to the difference in the coefficient of thermal expansion between the materials (37).

It is expected that the promising findings of the current study, discussed with results reported in previous investigations, may contribute to improve the adhesive bond between the fiberglass posts treated with experimental silanes and the root canal dentine, and possibly to predict the mechanical behavior of these associations in the oral environment when in use.

\section{Conclusion}

Based on findings of this study, the experimental silanes promoted different bond strength values in the adhesion of fiberglass posts to the root thirds, with better results for PETMP-HDDI silane. The root region did not influence the failure pattern and most slices showed mixed (MCDP) or adhesive (ADP) failures.

Türkçe Özet: Thio-Uretan esaslı deneysel silanlarla muamele edilmiş fiber postların adeziv dayanıklıı̆ı Amaç: Bu çalışmanın amacı thio-Uretan esaslı deneysel silanlarla muamele edilmiş fiber postların adeziv yapışma gücünü termo ve mekanik sikluslar sonrası değerlendirmektir. Gereç ve Yöntem: Sığır dişleri altı gruba bölünmüştür: RX-RU2 (RelyX CP + RelyX U200); PETMP-HDDI-RU2 (PETMP-HDDI + RelyX U200); PETMPBDI-RU2 (PETMP-BDI + RelyX U200); RX-RU (RelyX CP + RelyX Ultimate); PETMP-HDDI-RU (PETMP-HDDI + RelyX Ultimate); PETMP-BDI-RU (PET$M P-B D I+$ RelyX Ultimate). Her kökün üçte birinden bir dilim $(n=10)$ çekme testine tabi tutulmuş ve değerler $R$ istatistiksel analiz programı kullanılarak değerlendirilirken, başarısızlık paternleri yüzde hesabı ile belirtilmiştir. Bulgular: Üçte bir köklerden RX-RU2servikal ve apikalde daha fazla dayanıklılık göstermiş, PETMP-HDDI-RU2 tüm bölümlerde en yüksek değerleri vermiş, PETMP-BDI-RU2 ise apikalde daha fazla dayanıklılık göstermiştir. $R X-R U$ apikalde daha fazla dayanıklılık gösterirken, PETMP-HDDI-RU ve PETMP-BDI-RU tüm bölümlerde benzer dayanıklılık göstermiştir. Her üçte bir kökte PETMP-HDDI-RU2 tüm bölümlerde bölümlerde benzer dayanıklıık göstermiştir. Karışık ve adeziv başarısızlık daha çok olmuştur. Sonuç: Deneysel silanlar fiber postların üçte bir köklere yapışma kuvvetinde farklııklar göstermiş, PETMP-HDDI silanı daha iyi sonuç vermiştir. Kök bölgesi başarısızlık paternini etkilememiş ve tüm dilimlerde karışık (MCDP) ya da adeziv ( $A D P$ ) başarısızlık görülmüştür Anahtar kelimeler: Fiber post; Deneysel silan; Reçine siman; adeziv dayanıklılık; başarısızlık paterni

Ethics Committee Approval: Not required.

Informed Consent: : Not required.

Peer-review: Externally peer-reviewed.

Author contributions: VMP, CSP, APPF and RLXC participated in designing the study. VMP and RLXC participated in generating the data for the study. VMP, MCP, RAPR and RLXC participated in gathering the data for the study. VMP, MCP, RAPR and RLXC participated in the analysis of the data. VMP and RLXC wrote the majority of the original draft of the paper. VMP and RLXC participated in writing the paper. VMP, MCP, RAPR and RLXC have had access to all of the raw data of the study. VMP and RLXC have reviewed the pertinent raw data on which the results and conclusions of this study are based. All authors have approved the final version of this paper. VMP and RLXC guarantee that all individuals who meet the Journal's authorship criteria are included as authors of this paper. 
Conflict of Interest: The authors had no conflict of interest to declare.

Financial Disclosure: The authors declared that they have received no financial support.

Acknowledgements: The authors would like to thank the manufacturers Angelus and Ivoclar Vivadent for their valuable contribution with the materials used in this study.

\section{References}

1. Zicari F, Van Meerbeek B, Scotti R, Naert I. Effect of fibre post length and adhesive strategy on fracture resistance of endodontically treated teeth after fatigue loading. J Dent 2012; 40:312-21. [CrossRef]

2. Moraes A, Sarkis-Onofre R, Moraes R, Cenci MS, Soares CJ, Pereira-Cenci T. Can silanization increase the retention of glass-fiber posts? A systematic review and meta-analysis of in vitro studies. Oper Dent 2015;40:567-80. [CrossRef]

3. Tanoue N, Koishi Y, Atsuta M, Matsumura H. Properties of dualcurable luting composites polymerized with single and dual curing modes. J Oral Rehabil 2003;30:1015-21. [CrossRef]

4. Van Landuyt KL, Snauwaert J, De Munck J, Peumans M, Yoshida Y, Poitevin A. Systematic review of the chemical composition of contemporary dental adhesives. Biomaterials 2007; 28:3757-85. [CrossRef]

5. De Munck J, Vargas M, Van Landuyt K, Hikita K, Lambrechts $P$, Van Meerbeek B. Bonding of an auto-adhesive luting material to enamel and dentin. Dent Mater 2004;20: 963-71. [CrossRef]

6. Hikita K, Van Meerbeek B, De Munck J, Ikeda T, Van Landuyt $\mathrm{K}$, Maida T, et al. Bonding effectiveness of adhesive luting agents to enamel and dentin. Dent Mater 2007;23:71-80. [CrossRef]

7. Sarkis-Onofre R, Skupien JA, Cenci MS, Pereira-Cenci T. The role of resin cement on bond strength of glass-fiber posts luted into root canals: A systematic review and meta-analysis of in vitro studies. Oper Dent 2014;39:E31-44. [CrossRef]

8. Bacchi A, Consani RL, Martim GC, Pfeifer CS. Thio-urethane oligomers improve the properties of light-cured resin cements. Dent Mater 2015;31:565-74. [CrossRef]

9. Bacchi A, Yih JA, Platta J, Knight J, Pfeifer CS. Shrinkage/stress reduction and mechanical properties improvement in restorative composites formulated with thio-urethane oligomers. J Mech Behav Biomed Mater 2018;78:235-40. [CrossRef]

10. Consani RLX, De Paula AB, Fugolin APP, Pfeifer CS. Effect of the combination of a crosslinking agent and a thiourethane additive on the properties of acrylic denture bases processed with microwave energy. J Mech Behav Biomed Mater 2019;98:90-5. [CrossRef]

11. Pfeifer $C$, Lewis $S$. Thio-urethane oligomers as low-stress, tough additives in methacrylate polymerizations. IADR; 2012 (Abstract).

12. Pomini MC, Machado MM, Quadros GP, Gomes GM, Pinheiro LOB, Samra APB. In vitro fracture resistance and bond strength of self-adhesively luted cast metal and fiber-reinforced composite posts and cores: Influence of ferrule and storage time. Int J Prosthodont 2019; 32:205-7. [CrossRef]

13. El Mourad AM. Assessment of bonding effectiveness of adhesive materials to tooth structure using bond strength test methods: A review of literature. Open Dent J 2018;12:664-78. [CrossRef]

14. International Organization for Standardization. ISO TR11405: Dental materials - guidance on testing of adhesion to tooth structure. Geneva: International Organization for Standardization; 2014.

15. Core Team. A language and environment for statistical computing. R Foundation for Statistical Computing. Vienna, Austria; 2019.

16. Soares CJ, Santana FR, Castro CG, Paulo C F Santos-Filho, Paulo $\checkmark$ Soares, Fang Qian, et al. Finite element analysis and bond strength of a glass post to intraradicular dentin: comparison between microtensile and push-out tests. Dent Mater 2008;24:1405-11. [CrossRef]
17. Başaran G, Göncü Başaran E, Ayna E, Değer Y, Ayna B, Tuncer MC. Microtensile bond strength of root canal dentin treated with adhesive and fiber-reinforced post systems. Braz Oral Res 2019;33:e027. [CrossRef]

18. Ferrari M, Mannocci F, Vichi A, Cagidiaco MC, Mjör IA. Bonding to root canal: Structural characteristics of the substrate. Am J Dent 2000;13:255-60.

19. Demiryürek EO, Külünk $S$, Saraç D, Yüksel G, Bulucu B. Effect of different surface treatments on the push-out bond strength of fiber post to root canal dentin. Oral Surg Oral Med Oral Pathol Oral Radiol Endod 2009;108:e74-80. [CrossRef]

20. Li XJ, Zhao SJ, Niu LN, Tay FR, Jiao K, Gao Y, et al. Effect of luting cement and thermomechanical loading on retention of glass fibre posts in root canals. J Dent 2014;42: 75-83. [CrossRef]

21. Freitas TL, Vitti RP, Miranda ME, Brandt WC. Effect of glass fiber post adaptation on push-out bond strength to root dentin. Braz Dent J 2019;30:350-5. [CrossRef]

22. Gaston BA, West LA, Liewehr FR, Fernandes C, Pashley DH. Evaluation of regional bond strength of resin cement to endodontic surfaces. J Endod 2001;27:321-4. [CrossRef]

23. Kremeier K, Fasen L, Klaiber B, Hofmann N. Influence of endodontic post type (Glass fiber, quartz fiber or gold) and luting material on push-out bond strength to dentin in vitro. Dent Mater 2008;24:660-6. [CrossRef]

24. Suzuki T, Finger WJ. Dentin adhesives: site of dentin vs. bonding of composite resins. Dent Mater 1988;4:379-83. [CrossRef]

25. Ekambaram M, Yiu CKY, Matinlinna JP. Bonding of adhesive resin to intraradicular dentine: A review of the literature. Int J Adhes Adhes 2015;60:92-103. [CrossRef]

26. Macedo VC, Faria e Silva AL, Martins LRM. Effect of cement type, relining procedure, and length of cementation on pull-out bond strength of fiber posts. J Endod 2010;36:1543-6. [CrossRef]

27. Rodrigues RV, Sampaio CS, Pacheco RR, Pascon FM, PuppinRontani RM, Giannini M. Influence of adhesive cementation systems on the bond strength of relined fiber posts to root dentin. J Prosthet Dent 2017;118:493-9. [CrossRef]

28. Nihei T. Dental applications for silane coupling agents. J Oral Sci 2016;58:151-5. [CrossRef]

29. Chen JH, Matsumura $\mathrm{H}$, Atsuta M. Effect of etchant, etching period, and silane priming on bond strength to porcelain of composite resin. Oper Dent 1998;23:250-7.

30. Cramer NB, Couch CL, Schreck KM, Boulden JE, Wydra R, Stansbury JW, et al. Properties of methacrylate-thiol-ene formulations as dental restorative materials. Dent Mater 2010; 26:799-806. [CrossRef]

31. Bacchi A, Pfeifer CS. Rheological and mechanical properties and interfacial stress development of composite cements modified with thio-urethane oligomers. Dent Mater 2016;32:978-86. [CrossRef]

32. Hoyle CE, Bowman CN, Thiol-ene click chemistry. Angew Chem 2010; 49:1540-73. [CrossRef]

33. Oliveira AS, Ramalho ES, Ogliari FA, Moraes RR. Bonding selfadhesive resin cements to glass fibre posts: to silanate or not silanate? Int Endod J 2011;44:759-63. [CrossRef]

34. D'Arcangelo C, D'Amario M, Prosperi GD, Cinelli M, Giannoni M, Caputi S. Effect of surface treatments on tensile bond strength and on morphology of quartz-fiber posts. J Endod 2007;33:2647. [CrossRef]

35. Lazari PC, Oliveira RC, Anchieta RB, Almeida EO, Freitas Junior AC, Sidney Kina S, et al. Stress distribution on dentin-cementpost interface varying root canal and glass fiber post diameters. A three-dimensional finite element analysis based on micro-CT data. J Appl Oral Sci 2013;21:511-7. [CrossRef]

36. Bosso K, Gonini Junior A, Guiraldo RD, Berger SB, Lopes MB. Stress generated by customized glass fiber posts and other types by photoelastic analysis. Braz Dent J 2015;26: 222-7. [CrossRef]

37. Valdivia AD, Raposo LH, Simamoto-Junior PC, Novais VR, Soares JC. The effect of fiber post presence and restorative technique on the biomechanical behavior of endodontically treated maxillary incisors: an in vitro study. J Prosthet Dent 2012;108:147-57. [CrossRef] 